\title{
Ultrasonic treatment reduced residual monomer in methyl methacrylate-based orthodontic base-plate materials
}

\author{
Pajima Thaitammayanon $^{1}$, Chintana Sirichompun ${ }^{1 *}$ and Chairat Wiwatwarrapan ${ }^{2}$ \\ ${ }^{1}$ Department of Orthodontics, Faculty of Dentistry, Chulalongkorn University, Henri-Dunant Road, Bangkok 10330, Thailand \\ ${ }^{2}$ Department of Prosthodontics, Faculty of Dentistry, Chulalongkorn University, Henri-Dunant Road, Bangkok 10330, Thailand
}

\begin{abstract}
Objective: To evaluate the effect of ultrasonic treatment time on the level of residual monomer (LRM) in methyl methacrylate (MMA)-based orthodontic base-plate materials.

Methods: Forty-eight-disc specimens with a 50-mm diameter and 3-mm thickness fabricated from Orthocryl (OC, Dentaurum) and Orthoplast (OP, Vertex) selfcure acrylic were prepared according to their manufacturers' instructions and ISO 20795-2 (2013). They were randomly divided into eight groups (n=6): Group I, untreated controls; Groups II and III, immersed in room temperature water for 24 and $72 \mathrm{~h}$ respectively; Groups IV-VIII immersed in $50^{\circ} \mathrm{C}$ water in an ultrasonic bath for 3,5,10, 15 and 20 min respectively. The LRM was determined using a high-performance liquid chromatography. Data were analyzed by a one-way ANOVA, followed by Tukey's HSD post hoc test $(P<0.05)$.
\end{abstract}

Results: The LRM in OC II-VIII groups were significantly lower than those in the OP II-VIII, and were lower than that in the OC I. The LRM in OP III group was lower than that in the OP I. The LRM in OP VI-VIII groups were not significantly different from that in the OP III.

Conclusion: Water immersion at $50^{\circ} \mathrm{C}$ in an ultrasonic bath for 10-20 min reduced the LRM in MMA-based orthodontic base-plate materials. The results revealed a convenient reduction of the residual monomer within a short period of time in clinical practice.

\section{Introduction}

Orthodontic treatment can be with either fixed or removable appliances. Polymethyl methacrylate, acrylic resin has been widely used in the constructions of both active and passive removable orthodontic appliances for many years [1]. Orthodontic appliances are used for newborn patients with cleft lip and palate, space maintenance, tipping teeth, overbite reduction, thumb-sucking deterrence, block movements and retention after active treatment [2-4]. The appliances are used in children, adult and elderly patients. Moreover, the base plate of orthodontic appliance is kept in contact with oral mucosa for a long time during treatment.

For fabrication, two techniques are possible: a doughing technique, in which liquid and powder are mixed together, is widely utilized in prosthodontics. However, a spray-on technique, in which the polymer is saturated by its monomer, is commonly utilized in orthodontics for removable orthodontic appliances [5].

During the polymerization reaction of acrylic resin, not all of the methyl methacrylate (MMA) monomer is converted into polymer; unreacted monomer called residual monomer (RM) is left [6,7]. When the orthodontic base plate contacts saliva and mucosa, RM will be leached from the acrylic resin to the oral environment [8]. The RM has been reported toxicity and allergic reaction [9-12]. Allergy from the RM is varied among patients from a localized hypersensitive reaction to some systemic involvements [9,10,13-16]. In orthodontics, Gonçalves et al reported a 60-year-old woman who had an allergic reaction to the residual MMA after the insertion of a retainer for one month [9]. Consequently, it is desirable to reduce the residual MMA content in acrylic resin to as low a level as possible, prior to insertion in the patient's mouth.

In orthodontics, it has been recommended that the RM content of autopolymerized acrylic resin could be reduced by immersion in water for $24 \mathrm{~h}$ before usage [17]. In prosthodontics, it has been suggested that dentures should be immersed in water at $50^{\circ} \mathrm{C}$ for $60 \mathrm{~min}$ [18]. However, these methods take a long time to reduce the amount of RM. In some clinical situation, an immediate delivery of the removable appliance to the patient is needed, right after the repairing process and the fabricating an obturator to the cleft lip and palate newborn patient. Therefore, reduction of the RM level within a short period of time should be considered.

An ultrasonic bath is widely used for cleaning dental instruments. Several studies have reported the use of ultrasonic baths to extract chemical substances and nutrients in industry, e.g., extracting mangiferin from Mangifera indica leaves, oil from tobacco, and phenolic compounds from sugar cane [19-21]. Ultrasonic treatment has been firstly reported to reduce the RM level of autopolymerized acrylic resins used in prosthodontics [22]. However, its

Correspondence to: Chintana Sirichompun, Department of Orthodontics, Faculty of Dentistry, Chulalongkorn University, Henri-Dunant Road, Pathumwan Bangkok 10330, Thailand, Tel. +66 81 614 5548; Fax: +662218 8953, E-mail: schintan@chula.ac.th

Key words: high performance liquid chromatography, orthodontic base-plate materials, residual monomer, ultrasonic bath, water immersion

Received: January 02, 2018; Accepted: January 17, 2018; Published: January 19, 2018 
effectiveness in eluting RM from orthodontic acrylic resin has not been investigated.

The aim of this study was to evaluate the level of residual monomer (LRM) in MMA-based orthodontic base-plate materials after water immersion at room temperature and after immersion in an ultrasonic water bath under various treatment times.

\section{Materials and methods}

\section{Sample preparations}

Forty-eight disc specimens, $3 \mathrm{~mm}$ thick x $50 \mathrm{~mm}$ diameter, were prepared from each of two brands of MMA-based orthodontic base-plate materials, that is, Orthocryl (OC; Dentaurum, Ispringen, Germany) and Orthoplast (OP; Vertex Dental, Zeist, The Netherlands), by a spray-on technique (Table 1 ). The powder to liquid ratio was $2.7: 1$ in each specimen. The specimens were processed in accordance with the manufacturers' instructions and ISO 20795-2 (2013) [23]. Powder was placed into a stainless steel mold $(50 \pm 0.1 \mathrm{~mm}$ diameter and $3.0 \pm 0.1$ $\mathrm{mm}$ deep) and liquid dripped into the powder. The powder and the liquid were reapplied, until the mold was full. The specimens were placed in a pressure cooker for $20 \mathrm{~min}\left(0.22 \mathrm{MPa}\right.$ at $45^{\circ} \mathrm{C}$ for OC; 0.25 $\mathrm{MPa}$ at $55^{\circ} \mathrm{C}$ for $\mathrm{OP}$ according to the manufacturers' instructions), kept in the dark at $23 \pm 2^{\circ} \mathrm{C}$ for $24 \pm 5 \mathrm{~h}$, and wet-ground equally on both sides with P500 and P1200-grit silicon carbide papers. The specimens were checked with a digital caliper to ensure a diameter of $50 \pm 1 \mathrm{~mm}$ and a thickness of $2.0 \pm 0.1 \mathrm{~mm}$ (Table 1$)$.

Each brand was divided into eight groups, six specimens per group: Group I, untreated controls; Groups II and III immersed in water at room temperature for 24 and $72 \mathrm{~h}$ respectively; Groups IV-VIII immersed in water at $50^{\circ} \mathrm{C}$ in an ultrasonic bath at $40 \mathrm{kHz}$ for 3, 5, 10, 15 and 20 min respectively.

\section{Residual monomer extraction procedure following ISO 20795-2 (2013)}

Each specimen disc was first broken into small pieces. Approximately $650 \mathrm{mg}$ of each broken disc pieces were weighed by a digital scale (Sartorius BP110s, Sartorius, Germany) to four decimal places and treated with $10 \mathrm{ml}$ of tetrahydrofuran (Merck KGaA, Darmstadt, Germany) in a $10 \mathrm{ml}$ volumetric flask for each sample solution. The broken pieces from each specimen were distributed into three sample solutions for the pass/fail determination test for RM. The sample solution was agitated by a magnetic stirring apparatus at $25^{\circ} \mathrm{C}$ for $72 \pm 2 \mathrm{~h}$. A 2 -ml of the resultant slurry was transferred to a $10 \mathrm{ml}$ volumetric flask and methanol (Merck KGaA, Darmstadt., Germany) added to a total volume of $10 \mathrm{ml}$ and the solution shaken to precipitate the resin. A 5-ml aliquot was centrifuged at $3000 \mathrm{rpm}$ for $15 \mathrm{~min}$, and $3 \mathrm{ml}$ transferred to separate glass tubes. One $\mathrm{ml}$ of the supernatant of each sample was determined the monomer concentration by high performance liquid chromatography (HPLC) (Shimadzu 20A Prominence HPLC, Shimadzu Corporation, Kyoto, Japan) using a reverse-phase LC-18 (5- $\mu \mathrm{m}$ particle diameter, $46-\mathrm{mm}$ internal diameter x 150-mm length) analytical column. For the mobile phase, a solution of methanol-water (66:34 volume ratio) was used, with a $1.5 \mathrm{ml} / \mathrm{min}$ flow rate and a $205 \mathrm{~nm}$ UV detection wavelength.

\section{Residual monomer determination}

The amount of residual MMA was determined from a standard calibration curve $\left(\mathrm{R}^{2}>0.99\right)$ that was prepared by plotting the peaks of known amounts of MMA (approximately $6 \mathrm{mg}, 60 \mathrm{mg}, 150 \mathrm{mg}$,
$300 \mathrm{mg}$, and $400 \mathrm{mg}$ ). The standard curve was used to determine the concentration in micrograms of MMA, $\mathrm{c}_{\mathrm{MMA}}$, per milliliter of analyzed sample solution.

The standard calibration curve was calculated from known concentrations of MMA solution, which had the following equation $\left(\mathrm{R}^{2}>0.99\right)$ :

$$
f(x)=\left(2.67923^{\star} 10^{7}\right) x+454489
$$

Where $\mathrm{f}(\mathrm{x})=$ absorbance area of MMA by UV detector and $\mathrm{x}=$ MMA concentration

The total quantity of MMA in the sample solution, $\mathrm{m}_{\mathrm{MMA}}$, in micrograms, was calculated according to the following equation:

$$
m_{M M A}=\left[c_{M M A} \times\left(\frac{10}{2}\right)^{*} \times 10^{* *}\right]
$$

where ${ }^{*}$ is the tetrahydrofurane volume $(\mathrm{ml})$ and ${ }^{* *}$ is the methanol volume $(\mathrm{ml})$ used for extraction.

The RM (\%mg) was calculated using the following equation:

$$
\text { Residual monomer }(\% m g)=\frac{m_{M M A}}{c_{M M A}} \times 100
$$

Each specimen that was divided into three solutions (nine solutions in total) was tested for pass/fail determination of RM. The three solutions per sample were averaged to generate the representative value of each specimen. Therefore, six values were obtained for each experimental group. The data were analyzed with a one-way ANOVA, followed by Tukey's post hoc test at the $95 \%$ confidence level $(P<0.05)$ by the SPSS 17.0 software program (SPSS Inc., Chicago, IL).

\section{Results}

In the present study, we analyzed the LRM in orthodontic base polymers following the ISO method for the determination of RM. The three specimens that were divided into nine solutions were tested for pass/fail determination of RM, which is defined in ISO 20795-2 (2013). The maximum allowable RM is $5.0 \mathrm{mg} \%$. Our results indicated that all groups passed this requirement [23].

The results revealed statistically significant differences in the LRM after the different treatment methods (Table 2). The highest LRM was found in the OC I group, while the OC VIII group showed the lowest LRM.

According to a one-way ANOVA (Table 2), the LRM in OC II-VIII groups were significantly lower than that in the OC I $(P<0.001)$. The LRM in OC VIII group was significantly lower than those in the OC II and OC III $(P=0.034$ and $P=0.011)$. The LRM in OC VI and OC VII groups were not significantly different from those in the OC II $(P$ $=0.986$ and $P=0.209)$ and OC III $(P=0.999$ and $P=0.088)$, but the LRM in OC VII group was significantly lower than that in the OC VI $(P=0.003)$.

In the OP groups (Table 2), no significant difference existed between OP I and OP II groups $(P=0.241)$, but the LRM in OP III group was significantly lower than that in the OP I $(P<0.001)$. The LRM in OP VI-VIII groups were not significantly different from that in the OP III $(P=0.124, P=1.000$ and $P=0.430)$.

In the same treatment method, the OC samples had statistically significantly lower LRM than the OP samples $(P<0.001)$.

\section{Discussion}

Among the orthodontic literature, few studies have examined methods of reducing the LRM in orthodontic acrylic base-plate [24- 
Table 1. Chemical composition of MMA-based orthodontic base-plate materials

\begin{tabular}{|c|c|c|c|c|}
\hline Brand & Components & Composition & Manufacturer & Batch number \\
\hline \multirow[b]{2}{*}{$\begin{array}{l}\text { Orthocryl } \\
\text { (OC) }\end{array}$} & Powder & Polymethyl methacrylate & \multirow[b]{2}{*}{ Dentaurum, Ispringen, Germany } & 98210600 \\
\hline & Liquid & $\begin{array}{c}\text { Methyl methacrylate, } \\
\text { methyl acrylate, } \\
\text { methyl isobutyrate }>90 \% ; \\
\text { ethylene dimethacrylate }<10 \% ; \\
\text { 2-(2H-benzotriazol-2-yl)-p-cresol }<1 \%\end{array}$ & & 91839501 \\
\hline \multirow{2}{*}{$\begin{array}{l}\text { Orthoplast } \\
\quad \text { (OP) }\end{array}$} & Powder & $\begin{array}{c}\text { Polymethyl methacrylate }>99 \%, \\
\text { accelerator }<1 \%, \\
\text { color agents }<1 \%\end{array}$ & \multirow{2}{*}{$\begin{array}{l}\text { Vertex, Zeist, } \\
\text { The Netherlands }\end{array}$} & B4-957 \\
\hline & Liquid & $\begin{array}{c}\text { Methyl methacrylate }>95 \%, \\
\text { ethylene glycol dimethacrylate }<5 \%\end{array}$ & & 14003860 \\
\hline
\end{tabular}

Table 2. Means (wt $\%)$ and standard deviations of residual monomer concentration $(\mathrm{n}=6)$

\begin{tabular}{|c|c|c|c|}
\hline Group & Treatment & $\begin{array}{c}\text { Orthocryl (OC) } \\
(\mathbf{n = 6})\end{array}$ & $\begin{array}{c}\text { Orthoplast (OP) } \\
(\mathbf{n}=\mathbf{6})\end{array}$ \\
\hline I & Control & $3.31 \pm 0.18^{\mathrm{a}}$ & $3.27 \pm 0.10^{\mathrm{a}}$ \\
\hline Water, $\mathbf{2 5}^{\circ} \mathbf{C}$ & & & \\
\hline II & $24 \mathrm{~h}$ & $2.31 \pm 0.13^{\mathrm{e}, \mathrm{f}}$ & $3.06 \pm 0.09^{\mathrm{a}, \mathrm{b}}$ \\
\hline III & $72 \mathrm{~h}$ & $2.34 \pm 0.11^{\mathrm{e}, \mathrm{f}}$ & $2.75 \pm 0.04^{\mathrm{c}, \mathrm{d}}$ \\
\hline Ultrasonic bath, $\mathbf{5 0}^{\circ} \mathbf{C}$ & & & \\
\hline IV & $3 \mathrm{~min}$ & $2.70 \pm 0.22^{\mathrm{d}}$ & $3.08 \pm 0.06^{\mathrm{a}, \mathrm{b}}$ \\
\hline V & $5 \mathrm{~min}$ & $2.78 \pm 0.17^{\mathrm{c}, \mathrm{d}}$ & $3.14 \pm 0.03^{\mathrm{a}, \mathrm{b}}$ \\
\hline VI & $10 \mathrm{~min}$ & $2.42 \pm 0.13^{\mathrm{e}}$ & $2.98 \pm 0.10^{\mathrm{b}, \mathrm{c}}$ \\
\hline VII & $15 \mathrm{~min}$ & $2.10 \pm 0.20^{\mathrm{f}, \mathrm{g}}$ & $2.73 \pm 0.13^{\mathrm{c}, \mathrm{d}}$ \\
\hline VIII & $20 \mathrm{~min}$ & $2.04 \pm 0.08^{\mathrm{g}}$ & $2.56 \pm 0.08^{\mathrm{d}, \mathrm{e}}$ \\
\hline
\end{tabular}

Means with the same lowercase letter are not significantly different at $P<0.05$ by a oneway ANOVA with Tukey's HSD post hoc test.

26]. Consequently, this study investigated the effect of water immersion in an ultrasonic bath on the LRM in two different orthodontic acrylic resins.

High performance liquid chromatography, which is a wellestablished method for the determination of RM in dental acrylic resins [27-29], is non-destructive, enables simultaneous analysis of various substances, and provides correct estimates of the LRM in acrylic resin [30]. The HPLC was thus used in this study to determine the LRM.

The adverse effects of RM are patient allergy and its effect on physical properties of the acrylic. Orthodontic acrylic resins can cause toxic reactions in permanent cultures of fibroblasts and keratinocytes [31]. Moreover, Gonçalves et al reported an allergic reaction to MMA self-curing acrylic resin during an orthodontic treatment in a 60-yearold woman patient, after an orthodontic retainer had been inserted. A localized hypersensitive reaction on the palate, hypersalivation, a bitter taste in the mouth, and difficulty swallowing were reported [9].

The LRM in acrylic resin is also related to its physical properties. Dogan, et al. found a positive correlation between water sorption and RM. The RM can cause voids in acrylic resin, and when it leaches out, water molecules can penetrate the void and act as a plasticizer by pushing the polymer chains further apart [32]. Consequently, the secondary chemical bonding forces (van der Waals forces) between the polymer chains decrease, resulting in a reduction in physical properties. Other studies have demonstrated that physical properties are improved when the LRM is reduced [33,34].

According to ISO 20795-2, the LRM of orthodontic base polymers should not exceed $5 \mathrm{wt} \%$ [23]. In this study, each specimen complied with this requirement. Despite the fact that ISO 1567 was mentioned as a reference [35], LRM was limited to $4.5 \mathrm{wt} \%$ for self-curing acrylic resins. Harrison and Hugget referred to the British Standard Institute specification for self-curing orthodontic resin, which requires a 3.5 $\mathrm{wt} \%$ limit for the LRM [36]. However, Gonçalves et al reported an allergic reaction to the self-curing acrylic resin of an orthodontic retainer base plate [9], although the LRM $(\sim 0.75 \mathrm{wt} \%)$ were below the limits specified in product standards. Therefore, it is desirable to reduce the LRM in acrylic resin to as low a level as possible, prior to insertion into the patient's mouth.

The LRM in OC were significantly lower than those in OP after the same monomer elution protocol. This may be an influence of the particle size and the polymeric composition of the powder, as well as each brand's concentration of initiator and accelerator. The particle size of polymer resin influences the amount of monomer remaining in the polymer, and increasing amounts of accelerator in the liquid will tend to decrease the LRM after polymerization [24].

In the OC group, statistical analysis revealed that the LRM after water immersion at room temperature for 24 and $72 \mathrm{~h}$ were significantly less than that of the control group. These results were consistent with those reported by Stafford and Brook, in that the RM is lost rapidly in the first $24 \mathrm{~h}$ of water immersion [24]. The LRM in the orthodontic resins falls over time by two mechanisms: the continued polymerization of the monomer, and the leaching out of the monomer [37].

The LRM in OC IV-VIII groups were significantly lower than that in the OC I $(P<0.001)$. The LRM after water immersion at $50^{\circ} \mathrm{C}$ in an ultrasonic bath was reduced, probably because of the microscopic jets of liquid produced by the cavitation. The jets were able to enhance the leaching out of RM from the surface of specimen. Moreover, immersion in hot water $\left(50^{\circ} \mathrm{C}\right)$ promoted a more rapid diffusion of RM into water and increased polymerization at the sites of active radicals $[27,38]$.

The LRM of autopolymerized acrylic resins could be reduced by immersion in water for $24 \mathrm{~h}$ before usage [17,24], but a prolonged period is needed. On the other hand, immersion in an ultrasonic water bath needs less time to reduce the LRM in orthodontic base-plate materials. Therefore, the LRM in the orthodontic base-plate materials should be reduced by water immersion at $50^{\circ} \mathrm{C}$ in an ultrasonic bath for 10-20 min before delivery to the patients, when repairing and delivering an orthodontic appliance within a clinical visit.

Ultrasonic treatment with $50^{\circ} \mathrm{C}$ water may affect the amount of residual monomer in two ways. First, enhanced residual monomer reduction has been attributed to the propagation of ultrasound pressure and cavitation. The implosion of cavitation bubbles generates macroturbulence, high-velocity inter-particle collisions, and perturbation in acrylic resin micro-pores, which accelerates the eddy diffusion and internal diffusion of monomer [22]. Second, the increased water temperature increased the mobility of the monomer molecules leading to increased number of polymerized polymer chains and may result 
in higher monomer conversion compared with the untreated group. Future studies should focus on the elution of residual monomer into the environment coupled with the comparison of the degree of conversion before and after ultrasonic treatment. The properties of the acrylic resin, determined in ISO 20795-2, should also be investigated.

\section{Conclusions}

Using the same monomer elution method, the LRM in OC was lower than that in OP. Water immersion at $50^{\circ} \mathrm{C}$ in an ultrasonic bath for 10-20 min reduced the LRM in both MMA-based orthodontic baseplate materials, which was similar to or better than water immersion at room temperature for 24 and $72 \mathrm{~h}$. However, less time was required. The results revealed a convenient reduction of the residual monomer within a short period of time in the clinical practice.

\section{Author contribution}

Dr. Pajima Thaitammayanon participated in the literature search, laboratory work, data collection and manuscript drafting. Assoc. Prof. Chintana Sirichompun contributed to the idea and design of the study protocol, coordinated the research project and revised the manuscript critically for important intellectual content. Assoc. Prof. Chairat Wiwatwarrapan contributed to the idea and design of the study protocol, performed the statistical analysis and revised the manuscript critically for important intellectual content. All authors read and approved the final manuscript.

\section{Acknowledgements}

The authors are very grateful to Dr. Kevin Tompkins for his valuable commentary on the manuscript.

\section{Funding}

This study was supported by the Ratchadaphiseksomphot Endowment Fund of Chulalongkorn University (RES560530265-AS).

\section{Conflicts of interest}

The authors have no conflicts of interest relevant to this study.

\section{References}

1. Faltermeier A, Rosentritt M, Müssig D (2007) Acrylic removable appliances: Comparative evaluation of different postpolymerization methods. Am J Orthod Dentofacial Orthop 131: 301.e16-e22. [Crossref]

2. Littlewood SJ, Tait AG, Mandall NA, Lewis DH (2001) The role of removable appliances in contemporary orthodontics. Br Dent J 191: 304-306, 309-10. [Crossref]

3. Adams CP, Kerr WJS, Adams CP (1990) The design, construction, and use of removable orthodontic appliances. 6th edn. London: Butterworth-Heinemann:198.

4. Roberts-Harry D, Sandy J (2004) Orthodontics. Part 5: Appliance choices. Br Dent J 196: 9-18. [Crossref]

5. Bass NM (1983) Removable orthodontic appliance. Br Dent J 154: 281. [Crossref]

6. Anusavice KJ, Phillips RW (2003) Phillips' science of dental materials 11th edn. St. Louis: Saunders:106-110.

7. Zissis A, Yannikakis S, Polyzois G, Harrison A (2008) A long term study on residual monomer release from denture materials. Eur J Prosthodont Restor Dent 16: 81-84. [Crossref]

8. Kedjarune U1, Charoenworaluk N, Koontongkaew S (1999) Release of methyl methacrylate from heat-cured and autopolymerized resins: cytotoxicity testing related to residual monomer. Aust Dent J 44: 25-30. [Crossref]

9. Gonçalves TS, Morganti MA, Campos LC, Rizzatto SM, Menezes LM (2006) Allergy to auto-polymerized acrylic resin in an orthodontic patient. Am J Orthod Dentofacial Orthop 129: 431-435. [Crossref]
10. Ruiz-Genao DP, Moreno de Vega MJ, Sanchez Perez J, García-Díez A (2003) Labial edema due to an acrylic dental prosthesis. Contact Dermatitis 48: 273-274. [Crossref]

11. Lunder T, Rogl-Butina M (2000) Chronic urticaria from an acrylic dental prosthesis Contact Dermatitis 43: 232-233. [Crossref]

12. Gosavi SS, Gosavi SY, Alla RK (2010) Local and systemic effects of unpolymerised monomers. Dent Res J (Isfahan) 7: 82-87. [Crossref]

13. Chaves CA, Machado AL, Vergani CE, de Souza RF, Giampaolo ET (2012) Cytotoxicity of denture base and hard chairside reline materials: a systematic review. $J$ Prosthet Dent 107: 114-127. [Crossref]

14. Giunta J, Zablotsky N (1976) Allergic stomatitis caused by self-polymerizing resin. Oral Surg Oral Med Oral Pathol 41: 631-637. [Crossref]

15. Rose EC, Bumann J, Jonas IE, Kappert HF (2000) Contribution to the biological assessment of orthodontic acrylic materials. Measurement of their residual monomer output and cytotoxicity. J Orofac Orthop 61: 246-257. [Crossref]

16. Jorge JH, Giampaolo ET, Machado AL, Vergani CE (2003) Cytotoxicity of denture base acrylic resins: a literature review. J Prosthet Dent 90: 190-193. [Crossref]

17. Baker S, Brooks SC, Walker DM (1988) The release of residual monomeric methyl methacrylate from acrylic appliances in the human mouth: an assay for monomer in saliva. J Dent Res 67: 1295-1299. [Crossref]

18. Tsuchiya H, Hoshino Y, Tajima K, Takagi N (1994) Leaching and cytotoxicity of formaldehyde and methyl methacrylate from acrylic resin denture base materials. $J$ Prosthet Dent 71: 618-624. [Crossref]

19. Kulkarni VM, Rathod VK (2014) Mapping of an ultrasonic bath for ultrasound assisted extraction of mangiferin from Mangifera indica leaves. Ultrason Sonochem 21: 606-611.

20. Stanisavljevic IT, Lazic ML, Veljkovic VB (2007) Ultrasonic extraction of oil from tobacco (Nicotiana tabacum L.) seeds. Ultrason Sonochem 14: 646-652. [Crossref]

21. Feng S, Luo Z, Tao B, et al. (2015) Ultrasonic-assisted extraction and purification of phenolic compounds from sugarcane (Saccharum of?cinarum L.) rinds. LWT - Food Science and Technology 60: 970-976.

22. Charasseangpaisarn T, Wiwatwarrapan C (2015) The effect of various frequencies of ultrasonic cleaner in reducing residual monomer in acrylic resin. Ultrasonics 63: 163167. [Crossref]

23. International Organization for Standardization (2013) ISO 20795-2: Dentistry - Base polymers. Part 2: Orthodontic base polymers. Geneva: ISO. Available at: https://www. iso.org/standard/62279.html [Accessed September 30, 2017].

24. Stafford GD, Brooks SC (1985) The loss of residual monomer from acrylic orthodontic resins. Dent Mater 1: 135-138. [Crossref]

25. Goncalves TS, de Menezes LM, Silva LE (2008) Residual monomer of autopolymerized acrylic resin according to different manipulation and polishing methods. An in situ evaluation. Angle Orthod 78: 722-727. [Crossref]

26. Iça RB, Öztürk F, Ates B, Malkoc MA, Kelestemur Ü (2014) Level of residual monomer released from orthodontic acrylic materials. Angle Orthod 84: 862-867. [Crossref]

27. Vallittu PK, Miettinen V, Alakuijala P (1995) Residual monomer content and its release into water from denture base materials. Dent Mater 11: 338-342. [Crossref]

28. Shim JS, Watts DC (1999) Residual monomer concentrations in denture-base acrylic resin after an additional, soft-liner, heat-cure cycle. Dent Mater 15: 296-300. [Crossref]

29. Vallittu PK (1996) The effect of surface treatment of denture acrylic resin on the residual monomer content and its release into water. Acta Odontol Scand 54: 18811892. [Crossref]

30. Urban VM, Cass QB, Oliveira RV, Giampaolo ET, Machado AL (2006) Developmen and application of methods for determination of residual monomer in dental acrylic resins using high performance liquid chromatography. Biomed Chromatogr 20: 369376. [Crossref]

31. Schendel KU, Lenhardt M, Fusenig NE, Komposch G (1992) The testing of the toxicity of the plastics used in orthodontics. Fortschr Kieferorthop 53: 263-272. [Crossref]

32. Dogan A, Bek B, Cevik NN, Usanmaz A (1995) The effect of preparation conditions of acrylic denture base materials on the level of residual monomer, mechanical properties and water absorption. $J$ Dent 23: 313-318. [Crossref]

33. Urban VM, Machado AL, Vergani CE, Giampaolo ET, Pavarina AC, et al. (2009) Effect of water-bath post-polymerization on the mechanical properties, degree of conversion, and leaching of residual compounds of hard chairside reline resins. Dent Mater 25: 662-671. [Crossref] 
34. Patil PS, Chowdhary R, Mandokar RB (2009) Effect of microwave postpolymerization treatment on residual monomer content and the flexural strength of autopolymerizing reline resin. Indian J Dent Res 20: 293-297. [Crossref]

35. Yilmaz H, Aydin C, Caglar A, Yasar A (2003) The effect of glass fiber reinforcement on the residual monomer content of two denture base resins. Quintessence Int 34: 148153. [Crossref]
36. Harrison A, Huggett R (1992) Effect of the curing cycle on residual monomer levels of acrylic resin denture base polymers. $J$ Dent 20: 370-374. [Crossref]

37. Lamb DJ, Ellis B, Priestley D (1983) The effects of process variables on levels of residual monomer in autopolymerizing dental acrylic resin. J Dent 11: 80-88. [Crossref]

38. Lamb DJ, Ellis B, Priestley D (1982) Loss into water of residual monomer from autopolymerizing dental acrylic resin. Biomaterials $3: 155-159$. [Crossref]

Copyright: $(2018$ Sirichompun C. This is an open-access article distributed under the terms of the Creative Commons Attribution License, which permits unrestricted use, distribution, and reproduction in any medium, provided the original author and source are credited. 